\title{
Perceptions of a Glass Ceiling: A Cross-Cultural Analysis of Mexican and American Employees
}

Ashley J. Bennington, (Email: kfajb00@tamuk.edu), Texas A\&M University-Kingsville George R. Wagman, (Email: docwagman@sbcglobal.net), Texas A\&M University-Kingsville Michelle N. Stallone, (Email: michelle.stallone@tamuk.edu), Texas A\&M University-Kingsville

\begin{abstract}
This study asks employees in the United States and Mexico if they believe there is workplace discrimination based on gender, age, or ethnicity. As members of international organizations, the United States and Mexico have agreed to strive for the elimination of employment discrimination. Hypotheses based on Hofstede's Power Distance Index (PDI) predicted cultural differences in the two countries would result in a higher perception of workplace discrimination from employees in the United States than those in Mexico. The results support the hypotheses; directions are offered for future research.
\end{abstract}

\section{INTRODUCTION}

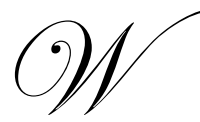

orkplace discrimination issues become international business concerns as the economies of different countries become more entwined in the global economy. The economic trade agreements between Mexico and the United States stimulate cross-cultural attention to labor standards and discrimination issues. Workplace discrimination exists in both countries. Several demographic indicators have been identified as barriers to advancement in employment: education, ethnicity, disability, age, and gender. Types of discrimination in employment practices include denial of access to jobs, lower pay, arbitrary termination, and lack of opportunities for advancement.

Most studies of workplace discrimination focus on disparities in numerical representation. These provide valuable measures of existing conditions. This study, however, asks employees in the United States and in Mexico if they perceive workplace discrimination based on gender, age, and ethnicity. Hofstede's theories of cultural dimensions support an expectation of greater awareness of workplace discrimination by employees in the United States than in Mexico.

\section{LABOR STANDARDS AGREEMENTS}

The United States and Mexico are members of several international organizations that establish or monitor employment issues globally, such as the International Labour Organization (ILO).The mission of the ILO, a United Nations affiliate, is to formulate "international labour standards in the form of Conventions and Recommendations setting minimum standards of basic labour rights (International Labour Organization, n.d.).

The North American Agreement on Labor Cooperation (NAALC), a side accord to the North American Free Trade Agreement (NAFTA), is an agreement on labor standards among the countries of Mexico, United States, and Canada. One of the twelve principles of NAALC is the elimination of employment discrimination (International Labour Organization, 2002). However, the basis of the agreement is that each country will enforce it own labor laws and compliance is voluntary (International Labor Rights Fund, 1995).

Both the U.S. and Mexico are members of the Organisation for Economic Co-operation and Development (OECD). A 2003 report from the Trade Union Advisory Committee to the OECD claims 'Employers' attitudes and 
practices need to be changed. There is ample evidence of widespread age discrimination in internal and external labour markets across OECD countries." The same report suggests that "...eliminating barriers to gender equality in the labour market must remain a high priority in all OECD countries" (Organisation for Economic Co-operation and Development, 2003). The OECD reports that in 2003, the employment rate for Mexican men was $80 \%$ but only $40 \%$ for Mexican women (Organisation for Economic Co-operation and Development, 2004).

\section{WORKPLACE DISCRIMINATION}

In the U.S., gender discrimination is often characterized by the term "glass ceiling," which was coined to describe the status of women in executive positions in major corporations (Hymowitz \& Schellhardt, 1986). Recent studies indicate that in spite of the legislation and increased awareness of discrimination issues, women still face barriers to advancement to executive and upper management positions (Lockwood, 2004). Pay disparities continue in executive or management positions between white males and women and minorities (e.g. National Committee).

Although the term glass ceiling generally brings to mind discrimination against women in major corporations, there is a broader definition. The Federal Glass Ceiling Commission described the glass ceiling as artificial barriers preventing women and minorities from advancement in the workplace (United States Department of Labor, 1995). Contributing reports to the Commission included studies of a wide variety of discrimination issues, including gender, ethnicity, disability, and education. One report prepared for the Commission emphasized the need for stimulating advancement opportunities at all levels of employment and in all three sectors of the economygovernment, for profit, and nonprofit (Burbridge, 1994).

Employment discrimination also exists in Mexico. In a 2002 report about Mexico to the United Nations General Assembly, the Committee on the Elimination of Discrimination Against Women expressed concern about "the meager 36 percent rate of participation of women in the economy and noted that one fourth of the female workforce earned less than the minimum wage" (United Nations, 2002). Although discrimination in hiring is an important issue, barriers preventing employed women and minorities to advance within their organization are more specific to the glass ceiling phenomena. The literature is sparse on the topic of advancement opportunities for women and minorities within Mexican organizations. There is no term or expression in Mexico comparable to the glass ceiling.

Rather than examine representation or pay disparities at the executive level, the broader glass ceiling concept stimulated this comparative study. The question this study seeks to illuminate is what are Mexican and American employee perceptions of workplace discrimination?

\section{CULTURAL DIFFERENCES}

Hofstede's theories of cultural differences guide this examination. Specifically, Hofstede's ratings of the Power Distance Index (PDI) for each country support predictions of differences in employee perceptions of the glass ceiling phenomena. ITIM: Culture and Management Consultants (n.d.) describes PDI:

Power Distance Index (PDI) focuses on the degree of equality, or inequality, between people in the country's society. A High Power Distance ranking indicates that inequalities of power and wealth have been allowed to grow within the society. These societies are more likely to follow a caste system that does not allow significant upward mobility of its citizens. A Low Power Distance ranking indicates the society de-emphasizes the differences between citizen's power and wealth. In these societies equality and opportunity for everyone is stressed.

In accordance with Hofstede's PDIs, Mexican employees (81 PDI) would not have as high expectations for equal opportunities as United States employees (40 PDI). This difference leads to the following hypotheses.

Hypothesis \#1: Employees in the United States will report a higher perception of a glass ceiling (gender, ethnic, age discrimination) than employees in Mexican companies. 
Hypothesis \#2: Women employed in U.S. companies will report a higher perception of a glass ceiling (gender, ethnic, or age discrimination) than women employed in Mexican companies.

To answer these questions, employees in the United States and in Mexico, employed in a variety of sizes and types of organizations, were surveyed about perceptions of gender, ethnic, and age discrimination issues.

\section{METHODOLOGY}

In the United States, 273 surveys were collected; 266 surveys were collected in Mexico. The total number of respondents was 539. The gender distribution was 139 male and 134 female U.S. respondents and 113 male and 153 female Mexican respondents.

A survey with yes or no response options was developed and translated into Spanish to solicit employee perceptions of several workplace issues. Permission was gained from management prior to conducting the on site surveys; participation was voluntary and a cover letter assured anonymity and provided for informed consent of the respondents. The surveys were conducted by five graduate students under the direction of Dr. George R. Wagman, Professor of Management, in the College of Business Administration of Texas A\&M University-Kingsville. The survey was conducted in three separate regions: Kansas, U.S., Texas, U.S., and Nuevo León, Mexico.

Respondents were asked for demographic information and several yes or no response survey questions. Three questions sought employee perceptions of discrimination in the workplace:

- $\quad$ Do you believe there is job discrimination based on gender?

- $\quad$ Do you believe there is job discrimination based on age?

- $\quad$ Do you believe there is job discrimination based on ethnicity?

\section{RESULTS}

\section{US/Mexico Comparisons}

\section{Country * Gender Discrimination}

A two-way contingency table analysis was conducted to evaluate whether the proportions of United States and Mexico employees who perceive gender discrimination were the same. The two variables in the analysis were country with two levels (United States and Mexico) and perception of gender discrimination with two levels (yes and no). Country and gender discrimination were found to be significantly related, Pearson $\chi^{2}(1, N=534)=83.94, p=$ .000 , Cramér's V $=.40$. The proportions of U.S. and Mexico employees who did perceive gender discrimination were .45 and .10 , respectively. Figure 1 represents the different rates of response for the variable gender discrimination by country. 


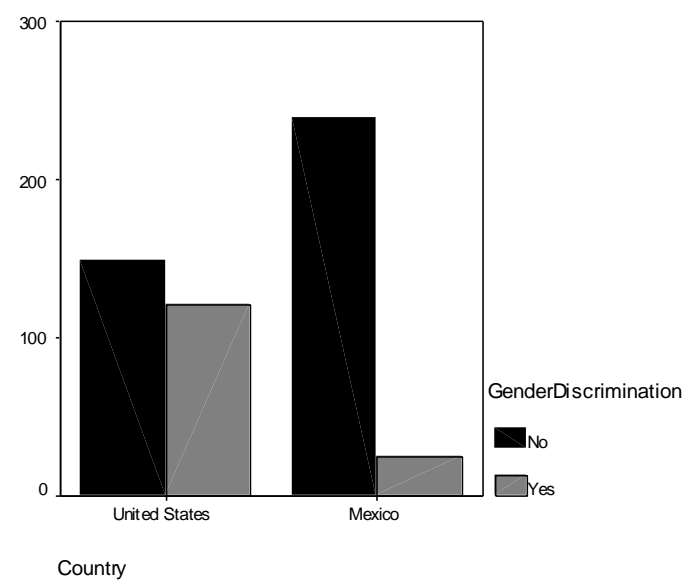

Figure 1: A Clustered Bar Chart Of Perceptions Of Gender Discrimination Within The Country Categories

\section{US/Mexico Comparisons}

Country * Age Discrimination

A two-way contingency table analysis was conducted to evaluate whether the proportions of United States and Mexico employees who perceive age discrimination were the same. The two variables in the analysis were country with two levels (United States and Mexico) and perception of age discrimination with two levels (yes and no). Country and age discrimination were found to be significantly related, Pearson $\chi^{2}(1, N=538)=92.41, p=.000$, Cramér's V $=.41$. The proportions of U.S. and Mexico employees who did perceive age discrimination were .40 and .05 , respectively. Figure 2 shows the different rates of response for age discrimination by country.

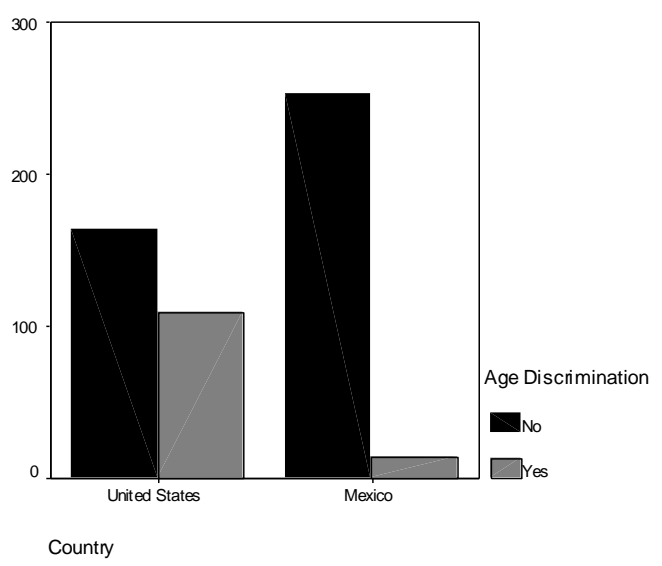

Figure 2: A Clustered Bar Chart Of Perceptions Of Age Discrimination Within The Country Categories

\section{US/Mexico Comparisons}

Country * Ethnic Discrimination

A two-way contingency table analysis was conducted to evaluate whether the proportions of United States and Mexico employees who perceive ethnic discrimination were the same. The two variables in the analysis were 
country with two levels (United States and Mexico) and perception of ethnic discrimination with two levels (yes and no). Country and ethnic discrimination were found to be significantly related, Pearson $\chi^{2}(1, N=536)=111.34, p=$ .000 , Cramér's V $=.46$. The proportions of U.S. and Mexico employees who did perceive ethnic discrimination were .44 and .05 , respectively. Figure 3 represents the different rates of response for the variable ethnic discrimination by country.

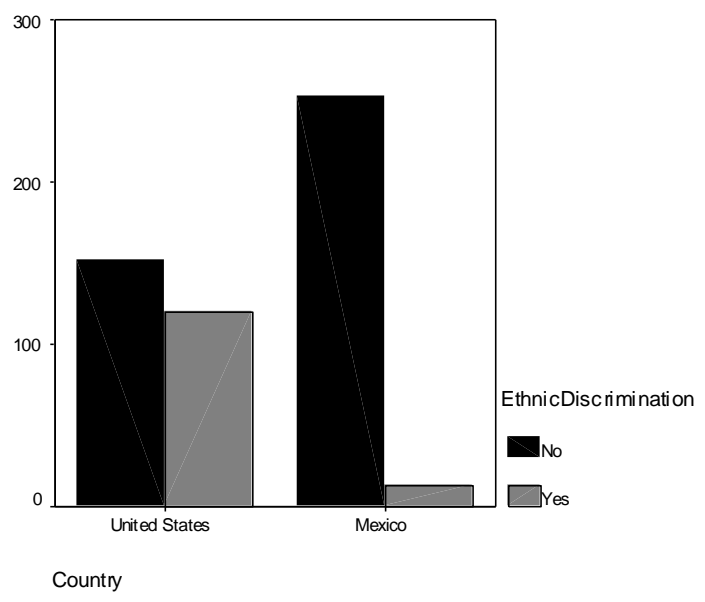

Figure 3: A Clustered Bar Chart Of Perceptions Of Ethnic Discrimination Within The Country Categories

Table 1

Female Respondents - Percent Perception of Workplace Discrimination, United States $n=134$, Mexico $n=153$

\begin{tabular}{|l|c|c|c|c|c|c|}
\hline \multicolumn{1}{|c|}{ Country } & \multicolumn{2}{|c|}{ Gender Discrimination } & \multicolumn{2}{c|}{ Age Discrimination } & \multicolumn{2}{c|}{ Ethnic Discrimination } \\
\hline & Yes & No & Yes & No & Yes & No \\
\hline United States & 46.6 & 53.4 & 39.1 & 60.9 & 39.4 & 60.6 \\
\hline Mexico & 11.1 & 88.9 & 4.6 & 95.4 & 3.9 & 96.1 \\
\hline
\end{tabular}

Table 2

Male Respondents - Percent Perception of Workplace Discrimination, United States $n=139$, Mexico $n=113$

\begin{tabular}{|l|c|c|c|c|c|c|}
\hline \multicolumn{1}{|c|}{ Country } & \multicolumn{2}{|c|}{ Gender Discrimination } & \multicolumn{2}{c|}{ Age Discrimination } & \multicolumn{2}{c|}{ Ethnic Discrimination } \\
\hline & Yes & No & Yes & No & Yes & No \\
\hline United States & 43.2 & 56.8 & 41.0 & 59.0 & 48.9 & 51.1 \\
\hline Mexico & 7.2 & 92.8 & 6.2 & 93.8 & 6.2 & 93.8 \\
\hline
\end{tabular}

\section{DISCUSSION}

H1: Employees in the United States will report a higher perception of a glass ceiling (gender, ethnic, age) than employees in Mexican companies.

The first hypothesis was supported by the data. In the combined categories (gender, age, ethnicity), the United States average shows $45 \%$ of employees believe there is workplace discrimination. An average of $10 \%$ of Mexican employees reported they believe there is workplace discrimination. The next step was to determine if there were differences between male and female respondents' perceptions, which is addressed in the second hypothesis. 
H2: Women employed in U.S. companies will report a higher perception of a glass ceiling (gender, ethnic, or age) than women employed in Mexican companies.

Again, the hypothesis predicting cultural differences between women in Mexico and the United States was supported. An average of the three categories shows a $41.7 \%$ yes response from U.S. women and a $6.5 \%$ average yes response from Mexican women.

These results may be moderated by the other cultural dimensions Hofstede (2001) identified and described (Fig. 4), particularly the Uncertainty Avoidance Index (UAI) of 82 for Mexico, which indicates "a preference for environments that are well-structured and defined and without conflict" (ITAP, n.d.).

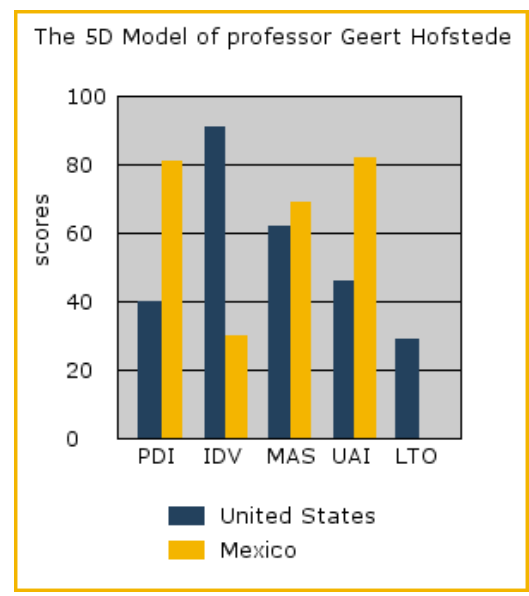

Figure 4: Comparison Of U.S. And Mexico On All Cultural Dimensions (Geert, N.D.)

\section{LIMITATIONS AND FUTURE RESEARCH DIRECTIONS}

Future examinations might explore differences in types of workplace, i.e. large or small, service or production, and government or private sectors. Another direction for research is an examination of age and length of employment in relation to perception of workplace discrimination. Job satisfaction and personal perception of promotion opportunities could also influence views of workplace discrimination.

\section{CONCLUSIONS}

The differences between Mexican and U.S. employees perceived workplace discrimination may be attributable to cultural awareness and government policies. The U.S. expression "glass ceiling" was originally coined to describe gender discrimination in access to executive positions in major U.S. corporations. However, the U.S. Federal Glass Ceiling Commission, which described gender, age, and ethnic discrimination barriers to advancement in the workplace, stimulated cultural awareness of employment discrimination in the United States.

Although employment discrimination exists in Mexico, there is no term or phrase comparable to glass ceiling to describe workplace barriers to advancement. Although studies exist on discrimination against pregnant women in the U.S.-Mexico border maquiladores (Koerner 1999), there is no substantial research on gender, age, or ethnic discrimination in Mexican employment.

This study initiated an examination of workplace discrimination from the employee's perspective rather than the standard measurements of representation and salary attainment. The cultural differences predicted by Hofstede's cultural dimensions theory were sustained by the data collected in this study. 


\section{REFERENCES}

1. Burbridge, L. C. (1994). The Glass Ceiling In Different Sectors of the Economy: Differences Between Government, Non-Profit, and For-Profit Organizations. Wellesley College Center for Research on Women,Wellesley, MA. Report submitted June 24, 1994 to The Glass Ceiling Commission, United States Department of Labor. Retrieved online at http://www.ilr.cornell.edu/library/downloads/keyWorkplace Documents/GlassCeilingBackground3SectorsEconomy.pdf.

2. Geert Hofstede ${ }^{\mathrm{TM}}$ Cultural Dimensions. (n.d.). Retrieved April 2, 2005 from ITIM: Culture and Management Consultants Web site: http://www.geert-hofstede.com/hofstede_dimensions.php?culture1=95\&culture2=59.

3. Hofstede, G. (2001). Culture's Consequence: Comparing Values, Behaviors, Institutions, and Organizations Across Nations. Thousand Oaks CA: Sage Publications.

4. Hymowitz, C. \& Schellhardt, T. D. (1986, March 24). The glass ceiling. The Wall Street Journal. Special Report on the Corporate Woman.

5. International Labour Organization. (n.d.) Retrieved July 9, 2004 from www.ilo.org/public/english/about/ index.htm.

6. International Labour Organization. (2002). The North American Agreement on Labour Cooperation. Retrieved July 9, 2004 from http://www.ilo.org/public/english/employment/gems/eeo/nafta/naalc.htm.

7. International Labor Rights Fund. (1995). North American Free Trade Agreement and Labor Rights. Retrieved July 9, 2004 from http://www.laborrights.org/publications/nafta.html.

8. ITIM: Culture and Management Consultants. (n.d.). Retrieved August 28, 2004, from http://www.geerthofstede.com/.

9. ITAP International. (n.d.). Retrieved April 2, 2005 from http://www.itapintl.com/ITAPCWfr.htm.

10. Koerner, R. S. (1999). Pregnancy discrimination in Mexico: Has Mexico complied with the North American Agreement on Labor Cooperation? Texas Journal On Civil Liberties \& Civil Rights, 4(2), 235-30.

11. Lockwood, N. R. (June 2004). The glass ceiling: Domestic and international perspectives. Society for Human Resource Management. Retrieved July 3, 2004 from http://www.shrm.org/research/quarterly/ 0402glass.asp.

12. National Committee on Pay Equity. (2004). The wage gap by education. Retrieved August 28, 2004 from http://www.pay-equity.org/info-education.html.

13. Organisation for Economic Co-operation and Development. (2003). TUAC Statement to the 2003 OECD. Meeting of Labour and Employment Ministers - Paris 29-30 September 2003. Retrieved July 7, 2004, from http://www.oecd.org/dataoecd/14/9/15486343.pdf.

14. Organisation for Economic Co-operation and Development. (2004). OECD employment outlook 2004. Retrieved July 9, 2004, from http://www.oecd.org/dataoecd/31/10/32566029.pdf.

15. United Nations. (2002). Report from the Committee on the Elimination of Discrimination Against Women. Retrieved July 7, 2004 from http://www.ishr.ch/About\%20UN/Reports\%20and\%20Analysis/CEDAW\%20$\% 20$ Ex\%20session\%2002.htm.

16. United States Department of Labor. (1995). Good for business: Making full use of the nation's human capital. Washington, D.C. (Also known as the Final Report of the Glass Ceiling Commission). Retrieved June 28, 2004 from http://www.ilr.cornell.edu/library/keyWorkplaceDocuments/government/federal/ Glassceilingreport.html. 


\section{NOTES}

